\title{
Project Inner Brick - Colorful Plastic Bricks in Psychotherapy - An Introduction to Methodology
}

\author{
László Neidert - Kinga Bíró
}

\begin{abstract}
PIB is a research project pertaining to the psychotherapeutic potential of Lego bricks. This is based on Lego Group's own method called Lego Seriousplay and Eric Berne's transactional analysis as a theoretical background. If we see it from the Lego's aspect, our plan is a training like LSP. It is only alike because of the special application. We made a lot of modifications according to the original methodology. In this document we would like to present details of our research we have been working on for almost two years. The characteristics of our methodology will be illustrated, too.
\end{abstract}

Key words: Lego Seriousplay, transactional analysis, counselling, psychotherapy, emotions.

\section{Introduction}

Project Inner Brick (PIB) is a new method for sharing psychological knowledge with others. We use Lego bricks and special playful triggers (i.e. games) based on personality theory concepts. The knowledge we share during our trainings can help participants to reach a better understanding of their lives, experiences and emotions. PIB can be used in different fields, like education, counselling and psychotherapy.

PIB is developed and tested by a research team with two psychologists. Our aim is to design an engaging material for clients and students that evokes positive associations. As far as professionals are concerned, PIB affords a lot of opportunities to them, too. Our game collection has a modular structure so one can design any theme he/she would like to. These custom designed game collections can refer to a situation, a problem, a setback or an educational need. PIB is a very effective and versatile method... not only for professionals but also families and parents.

In this article we are going to illustrate how a counsellor or a therapist can use the PIB method in a therapy or counselling setting.

* László Neidert, Pedagogical and Psychological Counselling Centre of Pécs, Hungary; laszlo.neidert@gmail.com

Kinga Bíró, Pedagogical and Psychological Counselling Centre of Pécs, Hungary; birokinga@icloud.com 


\section{Lego Group's method: Lego Seriousplay}

PIB is based on Lego Group's own method called Lego Seriousplay (LSP). It is mainly used in the field of organizational development and it was developed between 2001 and 2006 in the Swiss ImagiLab. The project leaders Bart Victor, Johan Roos and Robert Rasmussen designed a creativity and fantasy releasing tool which can be used to map the organizational identity and developing strategies, etc. (Gauntlett, 2007).

LSP has a really widespread theoretical background. The play is one of the main principles LSP is based on. The positive effects of playing take an effect and interlace all aspects of a human being. The positive effects of playing together are the developing of cooperative skills, and the strengthening of team cohesion. It helps us to experience and express the emotions and our life what gives us trust and the feeling of safety (Rasmussen, 2012).

Besides these, the cognitive theories and concepts like Piaget's constructivism and the constructionism of Pappert are part of the method as well as the specific thinking and the imagination (Rasmussen, 2012).

LSP is based on people's active theory which enables them to organize their knowledge. According to these the most effective learning and understanding is when we encounter things in the real world, when we design or build something real, or we build up knowledge (Rasmussen, 2012).

The storytelling and the metaphors during and after the building help this process. The tasks require fantasy which helps us understand and share the abstract concepts or theories (Rasmussen, 2012).

The facilitators who made the trainings designed games/tasks that gave the participants some kind of experience which Mihály Csíkszentmihályi called flow. With this method an optimal balance can be reached between the challenge and the skills. So it can be avoided that participants get bored, instead they have a good mood and experience effective learning (Rasmussen, 2012).

\section{Research fields of the LSP}

As far as the LSP research is concerned, there are a lot of different results. Jacobs and Heracleuos (2004) pointed out that the metaphors in general and the special types of them using Lego Seriousplay i.e. the embodied metaphors can help to deepen knowledge and unfold totally new narratives. The mapping of the organizational identity has a very good effect to develop new strategies as Bürgi and Roos (2002) called our attention to this. Nielsen (2009) has written about LSP, that it can facilitate communication and provide a common frame and share different aspects in the early state of development in interdisciplinary teams.

Moreover it can develop coping skills that has an effect on the team members. They can be better prepared, what helps them handle unexpected situations. Statler and Roos (2002) have written a summary about this topic. And last but not least, Gauntlett (2007) used the method for a sociological identity research. 


\section{About our method / The Project Inner Brick method}

The essence of the LSP's method is to use playful tasks that had been designed after a pre-arranged meeting. Participants' answers are their Lego constructions and the stories belonging to them. The professional who leads the training is called the facilitator. His role is to facilitate the process, share knowledge and make a common frame (Statler and Oliver, 2007).

A Project Inner Brick training looks very similar in practice. Since PIB is mainly based on LSP's methodology and its theoretical background, it has some rather important differences though. We use our own selection of Lego pieces instead of the original LSP set. We also use playful triggers which participants have to answer with their constructions and stories. However our triggers are based on personality theory concepts. Our aim is not only to build a common frame, but also to share psychological knowledge. The PIB trainer has to be a professional with field experience and theoretical knowledge. The PIB trainer is an independent expert. The topic and the theme of the particular training depend on: the situation, the group, the personal problem or obstacle, and the aims as well as the needs of the customer.

The idea of sharing professional knowledge in a therapeutic context stems from Eric Berne. He thought that the counselling process is more effective when the therapist shares his/her knowledge with the client. This kind of attitude benefits the clients' competence in organizing their own experiences and emotions. It also has a side effect, namely the 50-50\% splitting of the responsibility between the parties. It helps the client to avoid a symbiotic relationship (Berne, 1967).

We have chosen transactional analysis (TA) as a theoretical background not only for the previously mentioned reasons. TA is a remarkably expressive and picturesque personality theory and therapy method, and it is also very capable and versatile. It has a very wide application ranging from education through counselling and therapies to organizational development (Járó and Juhász, 1999).

When we compare the practical challenges of the TA method against the outcomes of the LSP research, we have to realize that the work with Lego bricks and the method's capabilities can complement flaws. A method like LSP can support professional therapists' work, for example, to conclude a psychological contract, to define the problem, to diagnose and to assign the heading of the counselling process (Járó and Juhász, 1999). This is based on the outcomes of the LSP research above. This can help the therapist to share the theoretical background and also a common frame with the client (Járó, 1999). This is important in a context like this, because the clients have to use this knowledge for realizing and changing their early decisions, and the programs that guide their lives and their beliefs (Berne, 1973). Furthermore, the clients can avoid, handle and stop the games they have been playing (Járó and Oláh, 1999; Berne, 1967). 


\section{The illustration of the PIB method in psychotherapy use}

Henceforth, we are going to show some examples (from our field research) to illustrate how PIB can be used in a psychotherapy context. Our intent is to demonstrate the role of a PIB trainer, and the difference between the therapy and educational usage of PIB.

Our research is in progress in different fields and contexts simultaneously. For example, we do research in counselling and therapy, child-rearing for families, education for children, adult education and supervising professional helpers. Our workflow usually has the following steps. First we do an interview in order to assess the demands and needs, and to discuss the possibilities. After this, we select the proper game, then we design a syllabus. At the end of the training or the counselling process we ask for feedback and share our results.

As far as the field of use is concerned, our method covers two main areas. Already at the beginning, it was important for us that our games can be used not only in a therapeutic context but also for educational or other purposes. When we design a game we attend to the fact that it can be used for various purposes. So the bases of our games are common, though there are some major differences between the therapy and the educational games.

The main difference is that it is not recommended to apply any psychotherapy technique in educational use. Students have the opportunity to work with their own experiences but it is not a prerequisite. The wording of the educational games is not intrusive. These offer knowledge and self-understanding yourself, but do not enforce it. The trainer doesn't use interpretation techniques even if a student takes advantage of the above opportunity.

As you will see further on, in counselling and therapy context, we always work with the client's own experiences. The trainer always interprets the client's projections in words or even with Lego bricks. After a sitting, and according to the client's reactions, we design and edit the next theme. In contrast to the educational usage of PIB, the themes and the order of the games are relatively adhered to.

Now we would like to illustrate with some brief examples how PIB counselling usage looks like in practice. Considering the limitations and the extent of our article we won't use special diagnostic and therapy phrases. We only would like to illustrate what kind of benefits the use of playful triggers and Lego bricks have. As you will see it has a lot of potential for the therapist as well as the clients.

\section{PIB therapy and diagnostic games}

As referred to earlier on, our first step is an interview. At the end of this first conversation we offer the client that we will approach his problem with a special method. Of course we share as many details of the PIB method as needed so that the client understands what it is all about. We tell him/her that we will give a set 


\section{Acta Technologica Dubnicae \\ volume 5, 2015, issue 1}

of playful tasks which are designed specifically for his problem or stop. And he has to answer or solve the tasks (i.e. games) with Lego models and stories.

We share some theoretical background with the client as well: for example, that this kind of approach, to build something, to confront things in the real world helps people to express their feelings and experiences. We call the client's attention to the fact that there is no wrong answer or model. Actually, we will work with metaphors so anything can be everything and every answer is a good one. The client can use the bricks not only for solving the tasks he got, but also any time and situation he would like to do so.

After that first sitting, we make an agreement with the client and design the games and build the theme for the next occasion.

Now, let's have a look at one of our cases. For Carl who had extreme mood swings and depression, we designed special games so that he will be able to better understand why these cloudy feelings pass away so slowly. One of Carl's answers is showed in the picture below...

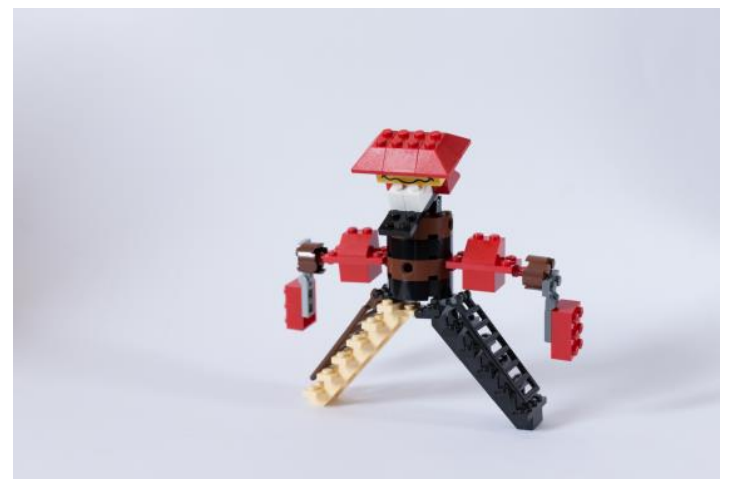

Figure 1 Carl's very first model

He explained to the therapist when he was in a gloomy mood, he looked like this model. When he felt uneasy, his arms dangled and his head was down. That was what he felt like when he was down. When the therapist asked him to look at the model and say something about his feelings and thoughts, which came to his mind, he listed a lot of negative emotions and thoughts.

For the trainer there was a lot more in this model than some kind of bad or uneasy feeling. It was like this figure hides its feelings. As though, there was some reason for suppressing and holding back. The head down rang the bell. I thought that there was some kind of shame there. To express these reflections the psychologist asked him "What if I modified the model a little bit?" He agreed. 


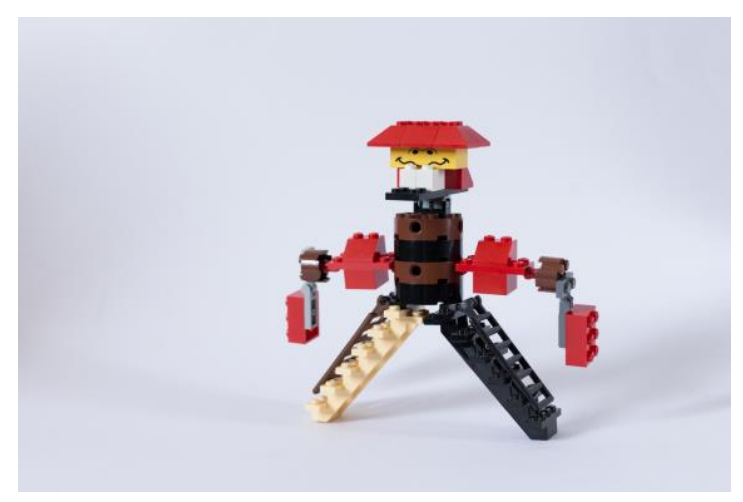

Figure 2 Carl's modified model

After the therapist had raised the model's head he asked him for some reflections. "Do you see any difference?" "What do you think now?" Carl said that it looked at him straight and it was strange, but not as bad... as it had been. "It is like it has no secrets, like it does not hide its feelings." "It looks straight into our eyes" - the therapist said. "Yes, maybe it is not ashamed of its bad or gloomy mood ... It is good for him..." - Carl said.

This was the subject the therapist wanted Carl to realize. Because it was highly possible that the shame was one of the components which had a leading role why his bad feelings stood with him so long. It was known from his stories that he was not aware of his feelings exactly, in which situations which emotion would be adequate. At the end of the sitting the therapist offered him that we should deal with the emotions in detail. They agreed that they made use of themes for sorting and realizing them. The model below is Carl's answer for one of the authentic feelings which is sadness... (Ian, 2014).

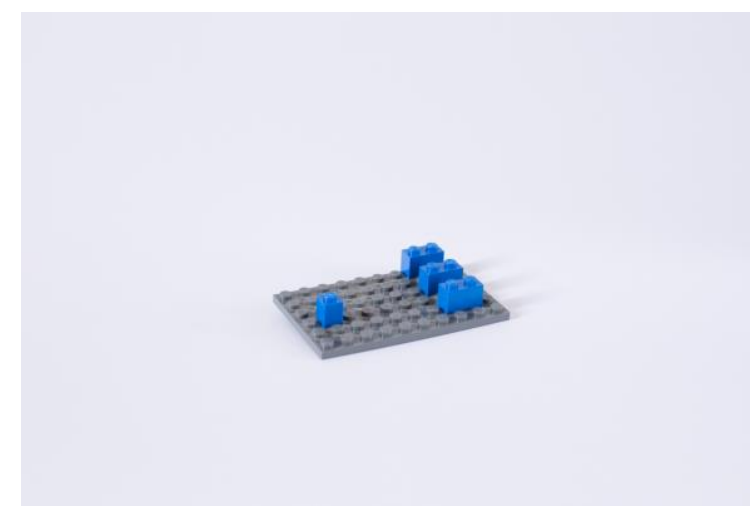

Figure 3 Carl's sadness-model 


\section{Acta Technologica Dubnicae \\ volume 5, 2015, issue 1}

Carl shared what it was about. "The one alone is the sad one. The others on the other side who together are in a good mood, they are having fun. This is how it is in my case" - he said. When he was in a bad mood, he always moved away. He was by himself rather than with others. The therapist asked him how long the gloomy feeling usually took. It took too long, he said. The therapist would like to clarify something so he asked him if he had been together with the others before the depression broke in, and if he moved away then. He verified this.

The psychologist asked him for permission to modify his model, because he had something in his mind that could be helpful. Carl said, yes.

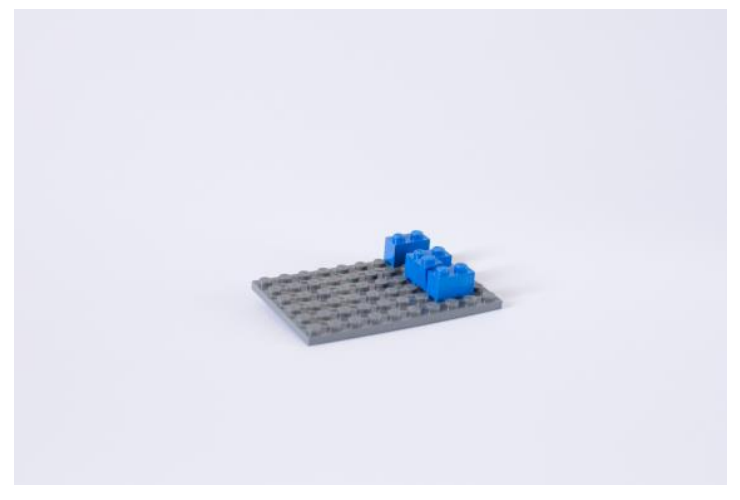

Figure 4 The modified sadness-model

The trainer inserted the sad brick into the group of happy bricks and asked him what his opinion of this modified situation was? He had never tried, he said; so he did not know. He thought a little, then added that it could help if he did not hold back but rather share his emotions with others... "Eventually I shared my bad feelings with you... and it is not that bad. It is totally different when I am alone with my thoughts and feelings."

The therapist pointed out that this was the major point. "What if, you would give it a try to share your emotions with somebody?" "You have a nice family, a lot of friends..." "Maybe, I will..." - said Carl.

\section{Summary}

It was the purpose to illustrate how intimate the work with Lego bricks could be. It has a wide range of possible applications. The client is not only able to express his emotions but the experiences can be literally touchable. PIB helps to put one's thoughts into words.

The therapist's intervention supports the client to realize and try out new and alternative solutions in a safe and inoffensive way. This method has a great 
potential with which professionals can be creative and react in a way no other methods allow.

\section{References}

BERNE, E. Games People Play: the psychology of human relationships. New York: Grove Press, 1967.

BERNE, E. What Do You Say After You Say Hello? The Psychology of Human Destiny. New York: Grove Press, 1973.

BÜRGI, P. T., and ROOS, J. Building Identity into Strategy. [online]. 2002. [viewed May 2013]. Avaible from:

$<\mathrm{http}: / /$ www.imagilab.org/pdf/np/np_vol1_no2_2002.pdf $>$

GAUNTLETT, D. Creative Explorations: New Approaches to Identities and Audiences. Routledge, 2007.

IAN, S. Transactional Analysis Counselling in Action. CPI Group (UK) Ltd., Croydon, 2014.

JACOBS, C., and COGHLAN, D. The Role of Listening in Organizational Learning. [online]. 2004. [viewed May 2013]. Avaible from: $<$ http://www.imagilab.org/pdf/wp04/WP41.pdf>

JACOBS, C., and HERACLEOUS, L. T. Constructing Shared Understanding: The Role of Embodied Metaphores in Organization Development. [online]. 2004. [viewed May 2013]. Avaible from:

$<$ http://www.imagilab.org/pdf/wp04/WP57.pdf $>$

JÁRÓ, K., and JUHÁSZ, E. Analysis and Change - A TA Guide. JÁRÓ, K. Without Games - Transactional Analysis in Practice. Helikon Kiadó, 1999.

JÁRÓ, K. Route Marks on the Map of the TA: Roots, Sources, and the Dilemmas of its Scientific Reception. JÁRÓ, K. Without Games - Transactional Analysis in Practice. Helikon Kiadó, 1999.

JÁRÓ, K., and OLÁH, ZS. Hatni mesterfokon. JÁRÓ, K. Without Games Transactional Analysis in Practice. Helikon Kiadó, 1999.

JUHÁSZ, E. They Don't Know Where the Borders Are: the Psychotherapy of Borderline Disorders. JÁRÓ, K. Without Games - Transactional Analysis in Practice. Helikon Kiadó, 1999.

LETICHE, H., and MAIER, J. The "Self" in Self-Organization. [online]. 2001. [viewed May 2013]. Avaible from:

$<$ http://www.imagilab.org/pdf/wp01/WP4.pdfs

NIELSEN, L. M. Personal - and Shared Experiential Concepts (PhD Dissertation). [online]. 2009. [viewed April 2013]. Avaible from: $<\mathrm{http}$ ://seriousplaypro.com/wp-

content/uploads/2010/08/Nielsen_PhD_2009_Personal_and_Shared_Experientia 1_Concepts.pdf

Rasmussen Consulting. The Science Behind the Lego Serious Play Method. [online]. 2012. [viewed April 2013]. Avaible from: 


\section{Acta Technologica Dubnicae \\ volume 5, 2015, issue 1}

$<$ http://www.rasmussenconsulting.dk/storage/The\%20Science\%20Behind\%20th e\%20LEGO\%20SERIOUS\%20PLAY\%20Method.pdf>

ROOS, M., and STATLER, M. Play and the Creative Arts: A review of Concepts and Techniques in the Psychotherapeutic Tradition. [online]. 2004. [viewed May 2013]. Avaible from:

$<$ http://www.imagilab.org/pdf/wp04/WP58.pdf>

SAID, R., ROOS, J., and STATLER, M. Lego Speaks. [online]. 2001. [viewed May 2013]. Avaible from: <http://www.imagilab.org/pdf/wp02/WP20.pdf $>$

STATLER, M., and ROOS, J. Preparing for the Unexpected. [online]. 2002. [viewed May 2013]. Avaible from:

$<$ http://www.imagilab.org/pdf/np/np_vol1_no3_2002.pdf >

STATLER, M., and ROOS, J. Everyday Strategic Preparedness: The Role of Practical Wisdom in Organizations. Palgrave Macmillan, 2007.

STATLER, M., and OLIVER, D. Facilitating Serious Play. [online]. 2007. [viewed April 2013]. Avaible from:

$<$ http://www.nyu.edu/intercep/Facilitating\%20Serious\%20Play\%20-

\%2015\%20Jan\%2007\%20-\%20AOM\%20acceptance.pdf>

VALKAI, ZS., and JÁRÓ, K. The Path to Psychic Health. JÁRÓ, K. Without Games - Transactional Analysis in Practice. Helikon Kiadó, 1999. 